\title{
Truthmakers and the direct argument
}

\author{
Charles Hermes
}

(C) Springer Science+Business Media Dordrecht 2013

\begin{abstract}
The truthmaker literature has recently come to the consensus that the logic of truthmaking is distinct from classical propositional logic. This development has huge implications for the free will literature. Since free will and moral responsibility are primarily ontological concerns (and not semantic concerns) the logic of truthmaking ought to be central to the free will debate. I shall demonstrate that counterexamples to transfer principles employed in the direct argument occur precisely where a plausible logic of truthmaking diverges from classical logic. Further, restricted transfer principles (like the ones employed by McKenna, Stump, and Warfield) are as problematic as the original formulation of the direct argument.
\end{abstract}

Keywords Free will · Direct argument - Moral responsibility · Truthmakers

Overspecialization often causes revolutionary breakthroughs in one area of philosophy to have little or no effect on related fields. For example, the truthmaker literature recently made drastic changes that are relevant to the free will debate. Nevertheless, the free will literature has yet to be modified by these developments.

In this paper, I shall develop counterexamples to the transfer principles employed in the direct argument (hereafter DA) that occur precisely where the recent developments in the truthmaker literature would predict. The DA concludes that nobody is responsible for anything in a deterministic world (van Inwagen 1980, 1983). Deterministic worlds are those in which the laws of nature and a complete description of the world at a time entail all true propositions. It seems clear that nobody is responsible for the state of the universe in the remote past or responsible

C. Hermes $(\bowtie)$

Department of Philosophy and Humanities, University of Texas-Arlington, 305 Carlisle Hall,

Box 19527, Arlington, TX 76019, USA

e-mail: hermes@uta.edu 
for the laws of nature. After all, before people were able to be responsible for anything it was already settled what the laws of nature are and what events occurred millions of years before life developed. Further, nobody is responsible for the fact that the laws and the past entail all true propositions in a deterministic world. The DA employs transfer principles to move from the fact that agents are not responsible for those facts to the claim that nobody is ever responsible for anything in a deterministic world. These transfer principles roughly claim that if an agent is not responsible for a proposition, and not responsible for the fact that the proposition entails some other proposition, then the agent is also not responsible for the derived proposition. Since, in a deterministic world, all true propositions are entailed by things that no agent is responsible for the DA concludes that nobody is responsible for anything in a deterministic world.

The DA is one of the most important arguments for incompatibilism. What makes the argument so impressive is that many of the arguments for incompatibilism start by attempting to demonstrate that determinism is incompatible with the ability to do otherwise. So, if the ability to do otherwise is required for moral responsibility, determinism is also incompatible with responsibility. Yet, today most opponents of incompatibilism accept that determinism is incompatible with the ability to do otherwise. Instead, they deny that the ability to do otherwise is required for moral responsibility. These semi-compatibilists can accept that many of the arguments for incompatibilism succeed. Only arguments that directly focus on moral responsibility and side-step the issue of whether agents have the ability to do otherwise must be rejected by semi-compatibilists. The DA is called the direct argument because it focuses directly on moral responsibility while side stepping the issue of whether agents are able to do otherwise. Since the DA threatens both semicompatibilists and the more traditional compatibilists it provides one of the most important arguments for incompatibilism.

While demonstrating that the DA fails is an important step in defending compatibilism, the methodological problems with the DA have significantly greater consequences for the free will literature. In the concluding section, I shall briefly discuss some of the other aspects of the free will literature that may be affected by further applications of the methodological lesson. First, however, it is important to understand what truthmakers are and how they have caused many philosophers to take the ontological turn in philosophy.

\section{Some background: the ontological turn, truthmakers, and truthbearers}

Kripke (1980) has taught us not to blur the distinction between analytic, necessary, and a priori truths. Prior to Kripke, the widespread belief that these classes of truths were co-extensive explained why many philosophers would slide between semantic, ontological, and epistemic concepts. If semantic concepts (like analyticity) were coextensive with ontological concepts (like necessity), the distinction would make little difference.

Disdain for metaphysics through most of the last century lead to frequent employment of semantic ascent. The process of semantic ascent modifies 
metaphysical questions into questions about the way we talk about these metaphysical issues. Ontology is thereby replaced by semantics. Allegedly, semantic ascent would allow progress in theoretical disputes while permitting participants in the debate to remain neutral on the metaphysical issues involved. It would be extraordinarily beneficial to employ semantic ascent in the free will literature, if the process were not problematic. After all, the wide range of specializations that are relevant to the free will debate makes free will one of the most challenging issues in philosophy. If the metaphysical issues involved could be bracketed at least some of the difficulty could be alleviated.

Recently, however, philosophers have become convinced that avoiding metaphysics is deeply problematic. Metaphysics has made such a miraculous recovery that many philosophers claim the linguistic turn and the conceptual turn have been replaced by the ontological turn. C.B. Martin is perhaps the most influential philosopher in bringing about the ontological turn. In his efforts to motivate this methodological approach he initiated much of the contemporary debate in dispositions and truthmakers.

Until recently, almost all philosophers believed that dispositions were analyzable in terms of single counterfactual conditionals. For example, live wires are those that would deliver a charge if they were to make contact with a conductor. Martin (1994) employed finkish dispositions as a counterexample to simple conditional accounts. A safety device that would cut the circuit upon sensing an approaching conductor could be attached to a live wire. Prior to the conductor's approach, the wire is live. Nevertheless, a charge would not be delivered if a conductor were to make contact with the wire. Instead, the safety device would have cut the circuit.

Martin believed these problems ought to cause theorists to abandon reductive accounts of dispositions. Instead, he claims that dispositions are a part of the fundamental ontology of the world. ${ }^{1}$ Others were not persuaded to abandon reductive accounts. For example David Lewis (2003) noticed that the safety device causes the intrinsic categorical properties of the wire to change. Further, some of these intrinsic categorical properties ground the fact that the wire is live. According to Lewis, live wires are those that would deliver a charge to a conductor if these intrinsic properties remained around long enough to bring about their typical effect. Many theorists, including myself, reject Lewis's account of dispositions but endorse some other reductive analysis. ${ }^{2}$ Yet, like Lewis's account, these alternative accounts are grounded in ontology and not mere semantics. Regardless of whether dispositions are a part of the fundamental structure of nature, or some reductive account can be provided, the ontology of dispositions has to be taken significantly more seriously because of Martin's work.

Today, almost everyone working on dispositions rejects the simple conditional analysis. Martin's technical point about dispositions, however, was intended as motivation for the ontological turn. If the simple conditional account of dispositions

\footnotetext{
${ }^{1}$ Bird (2010), Ellis (2007), Martin (2008), Molnar (2007), and Mumford (1998, 2004), provide booklength defenses of allowing dispositions into the basic ontology.

${ }^{2}$ While I believe that a reductive account of dispositions can be given, I do not believe that Lewis provides the best method for doing so. Yet, the account I defend (as well as all existing accounts of dispositions) takes the ontology of dispositions significantly more seriously (Hermes 2012).
} 
were correct, it would not be problematic to slide between the ontology of dispositions and the semantics of counterfactuals. After all, an object would have a dispositional property if and only if a particular counterfactual sentence was true of that object. Since the simple conditional account fails, we must take the ontology of dispositions significantly more seriously. Martin employed technical criticisms of the simple conditional account in order to motivate the ontological turn. My criticisms of the DA are intended in a similar vein. The technical problems with the DA are meant to illustrate why theorists in the free will debate ought to take the ontological turn.

Brilliant work by Kadri Vihvelin (2000, 2004, 2008, 2013), Michael Fara (2008), and Michael Smith (2003) has already drawn the attention of those working in the free will literature to this development in the dispositions literature. While developments in the dispositions literature help motivate the ontological turn, the contemporary truthmaker literature provides even stronger motivation for taking the ontological turn. ${ }^{3}$ Before exploring how the contemporary truthmaker literature affects the DA, it is important to explore what truthmakers are.

There is significant disagreement about what entities are the primary bearers of truth. Different theorists have proposed that beliefs, thoughts, ideas, judgments, statements, assertions, utterances, sentences, and propositions perform this task. The term truthbearer is utilized to refer to whatever it is that plays this essential role. Unfortunately, logicians do not employ the term truthbearer logic but instead often talk about propositional logic (or sentential logic). Yet, when logicians talk about propositional logic, they are not usually taking a stance on what the primary bearer of truth is. Instead, they employ the term 'proposition' in the same neutral sense that the term 'truthbearer' was coined to capture. Most philosophers believe that classical logic is the logic of truthbearers. Since classical logic preserves truth, it is primarily a logic for semantic concerns. At times I employ the term 'proposition' instead of 'truthbearer' because readers are significantly more familiar with it. However, I employ it in the logician's neutral sense. So, as I use it, the term 'proposition' is synonymous with 'truthbearer'.

Propositions, however, do not usually make themselves true. Instead, the proposition the cat is on the mat is true because of some aspects of the world. It seems obvious what makes it true that the cat is on the mat until we try to be more precise. When we try to be more precise, a host of options become available. Facts, states of affairs, events, things, and tropes, are just a few of the kinds of entities that have been claimed to do this work. While there are interesting debates on whether it is the event of the cat being on the mat or whether it is the state of affairs that makes the proposition true, it is often useful to bracket that debate so that we can move on to more important matters. The term 'truthmaker' is employed to provide a theoretically neutral manner to discuss whatever type of entity it is that makes truthbearers true.

\footnotetext{
${ }^{3}$ David Armstrong has perhaps had the greatest influence on getting philosophers to think about truthmakers. C.B. Martin, however, was the philosopher who convinced Armstrong of the importance of truthmakers.
} 
A logical system that preserves truth is essential for semantic issues. It is equally valuable, when dealing with ontological issues, to have a logic that preserves truthmaking. Engaging in philosophical disputes would be significantly simpler if the same logical systems could perform both tasks. In fact, the process of semantic ascent would not be as problematic if the same inferences were permitted for semantic and ontological issues. Yet, while there are excellent reasons to wish that the logics were the same this is unfortunately not the case. In the last decade, theorists working on the truthmaker literature have come to the consensus that the logic of truthmaking is not classical logic (Rodriguez-Pereyra 2006, p. 187).

Until recently, it was believed that classical logic was the logic that preserved truth and truthmaking. According to the classical truthmaker relation, for every object $\mathrm{x}$ and proposition $\mathrm{y}: \mathrm{x}$ is a truth-maker for $\mathrm{y}$ iff it is necessary that if $\mathrm{x}$ exists, $\mathrm{y}$ is true. It is relatively easy to show that on this account of truthmaking, truthmaking is preserved through classical entailment. After all if that $\mathrm{x}$ exists entails that $\mathrm{y}$ is true, and $\mathrm{y}$ entails that $\mathrm{z}$ is true then that $\mathrm{x}$ exists also entails that $\mathrm{z}$ is true. So, if $\mathrm{x}$ is a truthmaker for $\mathrm{y}$, and $\mathrm{y}$ entails $\mathrm{z}, \mathrm{x}$ is also a truthmaker for $\mathrm{z}$. In other words, according to the classical truthmaker relation, truthmaking is preserved under classical entailment.

George Restall demonstrated that the classical truthmaker relation entails that every object is a truthmaker for every true proposition (Restall 1996). To do so, he employed the following disjunction principle for truthmakers,

(DPT) if something makes a disjunction true, it must make at least one of the disjuncts true.

To generate the problem, consider disjunctions of the form $\mathrm{Av} \sim \mathrm{A}$ where $\mathrm{A}$ is true and $\sim \mathrm{A}$ is false and an arbitrary object $\mathrm{x}$. It is necessary that if $\mathrm{x}$ exists $\mathrm{A} v \sim \mathrm{A}$ is true. In fact, regardless of whether or not $x$ exists, it is necessarily true that $A v \sim A$. As was stated above, the classical truthmaker relation claims that $\mathrm{x}$ is a truth-maker for $y$ iff it is necessary that if $\mathrm{x}$ exists, $\mathrm{y}$ is true. So, $\mathrm{x}$ is a truthmaker for $\mathrm{A} \mathrm{v} \sim \mathrm{A}$. For the same reason, every object is a truthmaker for every logically necessarily true proposition. Given that the classical truthmaker relation employs classical entailment to preserve truthmaking this result is not too surprising. After all, every logically necessarily true proposition can be derived from any set of premises.

Yet, according to DPT, if $\mathrm{x}$ is a truthmaker for $\mathrm{A} v \sim \mathrm{A}$, it must also be a truthmaker for the true disjunct. Therefore, $\mathrm{x}$ is a truthmaker for A. Since A is an arbitrary true proposition, and $\mathrm{x}$ is an arbitrary object, we can conclude that every object is a truthmaker for every true proposition. Yet, it is obviously false that every object makes every true proposition true. My left shoe certainly does not make it true that Obama is president.

Worse yet, if every object makes every true proposition true, the way that the world is would be irrelevant to what is true at that world. Suppose that my left shoe is a truthmaker for the proposition that Obama is president. In that case, it would still be true that Obama is president in any world where my shoe exists, even if Obama did not exist in that world. Clearly, the classical relation mischaracterizes truthmaking. 
While many in the truthmaker literature believe that some form of relevant entailment captures the logic of truthmakers there is no consensus on what the logic of truthmaking is. Nevertheless, a series of arguments, like Restall's, has generated a consensus that it is not classical propositional logic. The logic of truthmakers and truthbearers is distinct.

\section{More background: the direct argument}

Free will and moral responsibility are ontological problems, not semantic problems. The primary concern of those interested in free will is with agents, their abilities, and the states of affairs that they bring about. We are only concerned about sentences describing agents and their activities insofar as those sentences help us understand the things they refer to. So, the logic of truthmaking, not truthbearing, ought to be central to the free will debate. Nevertheless, the DA transfers a lack of responsibility through classical entailment. Not surprisingly, counterexamples to the DA occur precisely where the logic of truthmakers diverges from classical logic.

The DA begins by noting that nobody is responsible for the state of the universe in the remote past or responsible for the laws of nature. Further, by the definition of determinism frequently employed in the free will debate, the laws of nature and complete description of the universe at any moment entail all true propositions. From these premises DA concludes that nobody is responsible for anything in a deterministic universe (van Inwagen 1980, 1983). To arrive at this conclusion, DA employs the following inference rules:

(A) From $\square$ p deduce NRs p.

(B) From NRs p and NRs(p $\supset$ q) deduce NRs $q$.

"NRs p" means "p and S is not now, nor ever has been, even partially responsible for the fact that p" and $\square$ symbolizes broadly logical necessity.

Mark Ravizza (1994) employed preemption cases to generate a counterexample to B. In preemption cases there are two different causal chains that would bring about an event on their own, but only one of the chains causes the event. For example, if two assassins attempt to kill the mayor, one could pull the trigger too late and merely shoot a corpse. While both assassins initiate causal chains that would lead to the death of the mayor, only the faster gunman killed the mayor. Preemption cases are also called cases of asymmetrical overdetermination. Symmetrical overdetermination differs from preemption in that both causal chains that would bring about the event are causes of the event. For example, both assassins would have caused the mayor's death if the bullets struck simultaneously. Later, I shall explore how symmetrical overdetermination causes problems for the DA. First, however, let us examine Ravizza's counterexample.

Suppose that Betty causes an avalanche by detonating explosives on a mountain. The avalanche then destroys an enemy camp at the base of the mountain. A second agent, however, is prepared to detonate explosives lower on the mountain in case Betty 
fails in her mission. Since Betty succeeded, the second agent did not need to act. Still, the plans of the second agent entail that the base will be destroyed. Further, Betty is not responsible for those plans. Yet, she is still responsible for the destruction of the enemy camp. Even though there is a proposition that entails that he enemy camp will be destroyed, and Betty is not responsible for that proposition, Betty is still responsible for the destruction of the enemy camp. So, B is an invalid inference rule.

Preemption cases, however, are drastically different from the threat of determinism. The plans of the second agent causally entail that the camp will be destroyed. Nevertheless, if determinism is true, the laws and the past logically entail all true propositions. Even though Ravizza demonstrated that B is invalid, this difference provides reason to believe that the DA can be revised to escape his challenge. In fact, restricting transfer principles so that they only apply to cases when the conditional is logically necessary produces a version of the DA that is immune to Rvizza's challenge. Ted Warfield (1996) presents the following transfer principle for this purpose.

\section{(B $\square$ ) From NRs p and $\square$ (p $\supset$ q) deduce NRs q.}

The plans of the second agent would cause the destruction of the enemy camp even if Betty had failed in her mission. Further, Betty is not responsible for those plans. Nevertheless, the plans of the second agent do not make it logically impossible for the camp to survive. Both Betty and the second agent could have failed in their missions. So, in Ravizza's counterexample, the second conjunct of $\mathrm{B} \square$ is false. Restricting transfer principles so that they only apply when the conditional is metaphysically necessary produces a variation of the DA that is immune to Ravizza's challenge.

Nevertheless, as I shall argue shortly, similar problems develop for restricted versions of the transfer principles. There is an important pattern that occurs in Ravizza's counterexamples. Although Betty could not render it false that the camp was destroyed she is responsible for its destruction. She is responsible because she made it true that the camp was destroyed. Further, Betty was not compelled to destroy the camp, but instead could have refrained from destroying the camp. While Betty made it true that the camp was destroyed, and could have refrained from making it true that the camp was destroyed, she could not have made it false that the camp was destroyed. Had Betty refrained from making it true that the camp was destroyed, the second agent would have made it true that the camp was destroyed. Counterexamples to the DA can be produced when an agent has the ability to make it true that an event occurs and has the ability to refrain from making it true that the event occurs but lacks the ability to make it false that the event occurs. In the next section I shall develop two counterexamples to $\mathrm{B} \square$ that share this pattern with Ravizza's case. The reason that this pattern creates problems for the DA, however, is because it provides a case where the logic of truthmakers diverges from classical logic. After providing two problems for B $\square$ that share the pattern of Ravizza's case, I provide a third type of counterexample that has a drastically different form. What all these problems for the DA have in common is that they develop where the logic of truthmakers diverges from the logic of truthbearers. The DA gains its plausibility through an illicit use of semantic ascent. 


\section{Logical problems for transfer principles}

Instead of relying on preemption cases, I shall concentrate on cases of symmetrical overdetermination. Yet, counterexamples to $\mathrm{B} \square$ cannot be produced by merely employing causal symmetrical overdetermination. Had Betty and the second agent both initiated causal chains that lead to the destruction of the enemy camp, it still would have been logically possible for the camp to survive. While detonating explosives lower on the mountain may have made it causally necessary that the camp was destroyed, it certainly would not have made it logically necessary.

Some propositions, however, are logically overdetermined. For example, disjunctions with two true disjuncts are logically overdetermined. The truth of either disjunct is logically sufficient for the truth of the disjunction. Logical overdetermination is as problematic for $\mathrm{B} \square$ as causal overdetermination is for B. Consider the following case.

Suppose that in order to destroy the enemy camp Amanda and Kate simultaneously and independently detonate explosives at different areas on a mountain. It is natural to believe that both are at least partially responsible for the fact that explosives were detonated in at least one of the two areas. Yet, given that their actions were independent, Amanda is not responsible for the fact that Kate detonated explosives. Further, the fact that Kate detonated explosives logically entails that explosives were detonated in at least one of the two areas. Since Amanda is not even partially responsible for a proposition that logically entails that explosives were detonated in at least one of the two areas, if $\mathrm{B} \square$ is valid, Amanda is not even partially responsible for the fact that explosives were detonated in at least one of the two areas of the mountain. The same argument demonstrates that Kate is also not even partially responsible for this fact. So, if $B \square$ is valid both failed in their mission to ensure that explosives were detonated in one of the two areas. $\mathrm{B} \square$ turns double success into failure. Yet, frequently multiple agents are independently responsible for the same proposition. Since $\mathrm{B} \square$ entails that this is impossible, $\mathrm{B} \square$ is an invalid inference rule.

Examining the logical structure of this case demonstrates that if $\mathrm{B} \square$ is valid there is a highly implausible theorem in the logic of moral responsibility. Consider the following argument form.

1. NRs $P$

2. $\square(\mathrm{P} \supset(\mathrm{PvQ}))$

3. NRs (PvQ)

4. NRs P $\supset$ NRs (PvQ)
(Assumption for $\supset$ introduction)

(v introduction)

(B $\square, 1,2)$

(つ introduction, 1-3)

If $\mathrm{B} \square$ is valid, 4 is a theorem in the logic of moral responsibility. The theorem claims that if an agent is not responsible for a true disjunct then the agent is not even partially responsible for the disjunction. Yet, when both disjuncts are true, an agent may be partially responsible for a disjunction without being responsible for both 
disjuncts. Instead, being responsible for one of disjuncts is usually sufficient for being at least partially responsible for the disjunction.

Existential introduction produces a similar problem. Suppose that Bob and Sue independently rob the same bank. Since their actions were independent, Bob is not responsible for the fact that Sue robbed the bank. Further, that Sue robbed the bank logically entails that someone robbed the bank. Clearly, however, that someone robbed the bank logically entails that the bank was robbed. Bob is not responsible for a proposition that logically entails that the bank was robbed. So, if $\mathrm{B} \square$ is a valid inference rule, Bob is not even partially responsible for the fact that the bank was robbed. A similar line of reasoning shows that Sue is also not responsible for the fact that the bank was robbed. While both Bob and Sue are responsible for the fact that the bank was robbed, if $\mathrm{B} \square$ were a valid inference rule neither would be responsible. Any logic of moral responsibility that makes $\mathrm{B} \square$ valid has as a theorem the following claim. Nobody can be even partially responsible for a proposition if another agent is also independently responsible for that proposition. Yet, frequently multiple agents are independently responsible for the same proposition. There are frequently many truthmakers for the same proposition.

The above problems stem from the fact that a proposition is either true or false. There is, however, a third option for truthmaking. An object can make a proposition true, make the negation of a proposition true, or neither make a proposition nor its negation true. For example, duckbilled platypuses are one of the things that make it true that some mammals lay eggs and one of the things that make it false that all mammals give live birth. Yet, duckbilled platypuses neither made it true nor made it false that I wrote this paper. Something might not be a truthmaker for a proposition and also not be a truthmaker for the negation of that proposition. ${ }^{4}$

Amanda made it true that explosives were detonated at one of the two areas of the mountain. Further, Amanda could have refrained from making it true that explosives were detonated. Yet, even if Amanda refrained from making it true that explosives were detonated, it still would have been true that explosives were detonated at one of the areas. Since Amanda cannot control Kate's behavior, Amanda could not have made it false that explosives were detonated at one of the two areas. Yet, Amanda is still responsible for what she did, and she could have done otherwise. Similarly, Bob made it true that the bank was robbed and had the ability to refrain from making it true that the bank was robbed. Nevertheless, because of Sue's actions, Bob could not have made it false that the bank was robbed. Bob is still responsible for making it the case that the bank was robbed, and could have been responsible for refraining from making it the case that the bank was robbed. Nevertheless, he could not have rendered it false that the bank was robbed.

\footnotetext{
4 This point seems relevant to many different areas of the free will debate. The consequence argument often conflates the ability to do otherwise with the ability to render a proposition false. Yet, doing other than making a proposition true need not require the ability to make the proposition false. Similarly, in Frankfurt cases, the fact that the agent cannot make it false that he performs some illicit activity allegedly demonstrates that he could not have done otherwise than make it true that he performs that activity. Yet, in the actual sequence of events, the agent's normal mental states make it true that he performs the activity. In the counterfactual scenario, a device that is not the agent's own makes it true that the illicit activity is performed. Like the consequence argument, Frankfurt cases seem to presume that the ability to do otherwise than make a proposition true requires the ability to make that proposition false.
} 
Propositions are either true or false. Nevertheless, there is a third option for truthmakers. An object can make a proposition true, make the proposition false, or neither make the proposition true nor false. This third option for truthmaking partially explains the difference between the logic of truthmakers and truthbearers. If free will and moral responsibility track truthmakers instead of truthbearers we would find counterexamples for $\mathrm{B} \square$ precisely where the above ones occur.

While $\mathrm{B} \square$ is invalid, perhaps further restrictions upon transfer principle could produce a sound version of the DA. Both Ravizza's case and the above cases are generated by forms of overdetermination. Ravizza's case provides causal overdetermination of the proposition, whereas the above cases produce logical overdetermination of the proposition. Some defenders of DA, however, favor restricting transfer principles so that they only apply when one sequence of events makes the proposition true (McKenna 2001; Stump 2000, 2002). Determinism does not allegedly prevent responsibility because the deterministic sequence of events and the agent's reasons for action both bring about the state of affairs. Instead, the deterministic sequence of events constitutes the agent's reasons for action (McKenna 2001, p. 45). One-path cases are allegedly the only relevant cases for the DA and restricting transfer principles so that they only apply to one-path cases seems to make the DA immune to overdetermination counterexamples.

There are excellent reasons to restrict transfer principles to one-path cases when considering causal overdetermination. The deterministic sequence of events and the agent's reasons for action certainly do not constitute two different causal chains that bring about the event. Yet, propositions about the deterministic sequence of events and propositions about the agent's mental states frequently logically overdetermine the truth of the relevant proposition. To avoid the above counterexamples, transfer principles must be restricted to one-path cases for logical overdetermination. Yet, it is unclear what the motivation for this restriction might be.

There seems to be little motivation for restricting transfer principles to one-path cases for logical overdetermination. More importantly, even if we were to restrict transfer principles to one-path cases for logical overdetermination, the restricted principle would still be invalid. If counterexamples to $\mathrm{B} \square$ can be generated whenever the logic of truthmakers diverges from the logic of truthbearers, then counterexamples can be generated without relying upon overdetermination cases. Before developing this type of a counterexample it is necessary to explore what counterfactuals are and two plausible principles.

Counterfactuals are sentences of the form, if $\mathrm{P}$ were true then $\mathrm{Q}$ would have been true, and are symbolized as $\mathrm{P} \square \rightarrow \mathrm{Q}$. The standard semantics for counterfactuals claims that $\mathrm{P} \square \rightarrow \mathrm{Q}$ is non-vacuously true if and only if some world where both $\mathrm{P}$ and $\mathrm{Q}$ are true is more similar to the actual world than any world where $\mathrm{P}$ is true and $\mathrm{Q}$ is false (Lewis 1973). Not all counterfactuals have false antecedents. ${ }^{5}$ Instead

\footnotetext{
5 Theorists in the counterfactuals literature tend to follow David Lewis by using the term 'counterfactual' even for conditionals with true antecedents. Psychologists, working on counterfactual reasoning, often restrict the term 'counterfactual' only for conditionals where the antecedent is false and use the term 'subjunctive' for a broader class of conditionals. While I follow Lewis in my usage of the term 'counterfactual' nothing would be lost by replacing all occurrences of the term 'counterfactual' with 'subjunctive conditional'.
} 
they are named 'counterfactuals' because (on standard accounts) they operate like material conditionals except when their antecedents are false. More importantly, any counterfactual with a true antecedent and a false consequent is false. In other words, modus ponens is a valid inference rule for counterfactuals. Further, material conditionals are only false when their antecedent is true and their consequent is false. So, counterfactuals are false in the only cases in which a material conditional is false. Whenever a counterfactual conditional is true, the corresponding material conditional is also true. In other words, counterfactuals entail corresponding material conditionals (I shall refer to this inference as "C2M").

The second principle stems from considering moral responsibility for disjunctions. Any plausible account of moral responsibility must make the following disjunction principle true:

(DPR) If a disjunction has only one true disjunct, and an agent is responsible for the truth of that disjunct, then the agent is responsible for the truth of the disjunction.

To see why this inference is required, suppose that Mary knows that one of her two children broke her favorite vase and wants to know who is responsible. Mary would discover what she wanted to know by learning that Johnny is the only person responsible for breaking the vase. After all, if Johnny is the only person responsible for breaking the vase, then Johnny is also responsible for the fact that one of her children broke the vase. It is easy to see how Mary can derive this conclusion, if DPR is valid. If DPR is invalid, Mary's inference appears to be equally problematic.

DPR is interestingly similar to DPT. According to DPT, whatever makes a disjunction true must make at least one of its disjuncts true. So, if a disjunction has only one true disjunct, and an agent produces the truthmaker for that disjunct, then the agent produces at least one of the truthmakers for the disjunction. If responsibility tracks truthmaking, DPR can be derived from DPT. Further, since the earliest counterexamples to the classical view of truthmaking stemmed from DPT, if responsibility tracks truthmaking there is reason to believe that we could generate counterexamples to $\mathrm{B} \square$ from DPR. As we shall see any logic of moral responsibility that includes $\mathrm{B} \square, \mathrm{DPR}$, and $\mathrm{C} 2 \mathrm{M}$ will have problematic consequences.

Upset with her husband, Patricia replaced his heart medications with a placebo. A few days later, her husband died of a heart attack. When interrogated, Patricia employed the following defense. "My husband did not survive. Yet, I am not even partially responsible for the fact that had he taken his medications he would have survived. I unfortunately do not deserve credit for the causal efficacy of the medication (although I would certainly accept any monetary compensation I am owed if you disagree). Since I am not even partially responsible for that counterfactual, and counterfactuals entail material conditionals, I am also not even partially responsible for the fact that if my husband took his medication he survived. In other words, I am not even partially responsible for the fact that either my husband did not take his medication or else he survived. Yet, since that disjunction has only one true disjunct, I would have been responsible for the disjunction if I were responsible for the true disjunct. Since I am not responsible for the disjunction, 
I am also not responsible for its only true disjunct. Therefore, I am not responsible for the fact that my husband did not take his medications. I'm innocent of any wrongdoing."

Patricia's argument is clearly invalid. Patricia's husband died, and he would have survived had he taken his medication. It does not follow from this, however, that Patricia isn't responsible for the fact that her husband did not take his medicine. Had she not replaced the medication with a placebo, he would have taken the medication. Patricia, however, only employed C2M, B $\square$, DPR and standard inferences of classical logic in her argument. Unless one of those inferences is invalid, Patricia's argument is sound. Examining the logical structure of Patricia's argument demonstrates that these are the only inferences she employed. When we symbolize "Patricia's husband survived" as S, "Patricia's husband takes his heart medication" as T, and Patricia as p, the following argument form captures Patricia's defense.
1. $\sim \mathrm{S} \& \mathrm{NRp} \mathrm{T} \square \rightarrow \mathrm{S}$
(premise)
2. $\square((\mathrm{T} \square \rightarrow \mathrm{S}) \supset(\mathrm{T} \supset \mathrm{S}))$
3. NRp (T つ S)
4. $\square((\mathrm{T} \supset \mathrm{S}) \supset(\sim \mathrm{TvS}))$
(implication)
5. NRp $(\sim \mathrm{TvS})$
$(\mathrm{B} \square, 3,4)$
6. NRp $\sim \mathrm{T}$
$(\mathrm{DPR}, 1,5)^{6}$

While Patricia's argument is deeply problematic, the principles she employs are all independently plausible. Earlier, I have argued that DPR is essential for any plausible logic of moral responsibility. Further, C2M (or a restricted version strong enough to generate these results) is a valid inference rule on all existing accounts of counterfactuals. ${ }^{7}$ So, it seems that if $\mathrm{B} \square$ is a valid inference rule, Patricia's argument is sound.

Further exploration demonstrates that the problematic inference occurs on line 3. This inference claims that if Patricia is not responsible for the fact that her husband would have survived had he taken his medications, and counterfactuals entails corresponding material conditionals, then Patricia is not even partially responsible for the material conditional. Certainly, Patricia is not responsible for the fact that her husband would have survived had he taken his medication. She is, however, responsible for the fact that her husband did not take his medication. In other words, she is responsible for making the antecedent of that counterfactual false. One cannot

\footnotetext{
6 A similar argument occurs in (Hermes and Campbell 2012).

7 While $\mathrm{C} 2 \mathrm{M}$ as it is defined here is a principle in standard accounts of counterfactuals, there are a few alleged counterexamples to C2M in the counterfactuals literature (Gundersen 2002, 2003, 2004; Lycan 1993, 2001; McDermott 2007, and McGee 2000, 2007). One type of counterexample occurs in cases of iterated counterfactuals. These alleged counterexamples have the form 1. P $\square \rightarrow(\mathrm{Q} \square \rightarrow \mathrm{R})$, 2. P, therefore 3. Q $\square \rightarrow$ R. A second alleged counterexample occurs when a bizarre unexplained event prevents the consequent from being true when the antecedent is true. Those who accept these counterexamples still endorse a restricted version of $\mathrm{C} 2 \mathrm{M}$ that applies when the contested patters are not an issue. Since neither of the contested patterns are employed in the above argument, even those who reject the standard version of $\mathrm{C} 2 \mathrm{M}$ could employ a restricted version and derive the same results.
} 
make a counterfactual true, however, by merely making its antecedent false. Counterfactuals with false antecedents are not trivially true.

Nevertheless, Patricia does make the corresponding material conditional true. Material conditionals with false antecedents are trivially true. By making the antecedent of the conditional false, Patricia produces a truthmaker for the material conditional. While Patricia does not make the counterfactual true, and the counterfactual entails the material conditional, Patricia does make the material conditional true. If responsibility tracks truthmaking, Patricia is not responsible for the counterfactual but is responsible for the material conditional. So, the inference at 3 is invalid.

The DA is one of the most important arguments for incompatibilism. By sidestepping the issue of whether an agent has the ability to do otherwise, it provides a powerful criticism of both classical and semi-compatibilism. Yet, the DA is problematic because it is not direct enough. Any argument demonstrating that agents lack free will in a deterministic world must be an argument about agents and the states of affairs that they bring about. After all, free will is about those aspects of the world. Yet, while free will is about those aspects of the world, the DA concentrates on which propositions are true in a world. Given this change in topic, it is not surprising that the DA fails precisely where a plausible logic for truthmaking diverges from classical propositional logic. In other words, the DA fails because it attempts to solve an ontological problem by concentrating purely on semantic issues.

Incompatibilism gains much of its plausibility from semantic ascent. In a deterministic world, statements about laws of nature and a complete description of the world at some moment entail all true propositions. The difficult task for the incompatibilist is demonstrating how these semantic claims affect the ontological issues we care about. Carelessly sliding from semantic concerns to ontological concerns makes it seem that the past and the laws that make those propositions true. Similarly, this slide makes it seem that the laws and the past are responsible for the truth of future propositions. When we recognize that semantic ascent is often problematic, much of incompatibilism's initial appeal is lost. Semantic arguments are insufficient for demonstrating that moral responsibility, or the ability to do otherwise, is incompatible with determinism. The difficult task for the incompatibilist is demonstrating how these semantic claims entail something interesting about the world. Yet, many of the arguments for incompatibilism (including the DA) are mere semantics that never make this important step.

\section{The ontological turn and free will}

Someone unaware of the disdain for metaphysics that existed throughout most of the last century, and how semantic assent allegedly allowed theorists to avoid ontology, would find much of the contemporary free will literature perplexing. While we are concerned about whether agents could act differently in deterministic worlds, we quickly shift to discussing whether agents can render propositions false. Similarly, while we initially think of determinism as a thesis about the way the world is, we define determinism as a relationship between propositions. Further, while we may 
worry that the forces described by statements of laws of nature could force agents to behave in particular ways, we define laws in semantic terms. Yet, nobody has ever been pushed around by a proposition.

As we become entrenched in the free will debate, this perplexity subsides. The belief that these semantic concepts are close enough to what we originally cared about, and significantly easier to work with, causes many theorists to assume that this escape to the semantic plane is not problematic. Surprisingly, philosophers who are typically meticulous about conceptual clarity often ignore the fact that the semantic concepts they work with are distinct from the ontological concepts they care about.

Yet, in the last few decades, philosophers have returned to ontology. The belief that the distinction between ontological concepts and semantic concepts makes no difference is frequently confronted with counterexamples. Hopefully, the above discussion of the DA has convinced readers that the ontological turn in philosophy is relevant to the free will debate. Yet, there are many other reasons why it is important for philosophers in the free will literature to take the ontological turn.

A single paper could not fully explore the importance of the ontological turn for free will. After all, once one takes the ontological turn much of the free will literature seems deeply problematic. While I cannot fully develop the consequences of the ontological turn for free will here, hopefully seeing how the core concepts in the free will literature have been shaped by the linguistic turn will provide some indication of how important the ontological turn is for the free will debate. By briefly exploring the semantic concepts of determinism and laws of nature that are central to the free will debate we shall see that the ontological turn has extreme consequences for free will.

Standard definitions claim that a world is deterministic if and only if the laws of nature and a complete description of the world at some moment logically entail all true propositions. This is clearly a semantic definition of determinism. David Lewis, who was keenly aware that sliding between ontology and semantics is often problematic, employed a less standard definition of determinism. Lewis (1986, p. 37) claims, "a deterministic system of laws is one such that, whenever two possible worlds both obey the laws perfectly, then either they are exactly alike throughout all of time, or else they are not exactly alike through any stretch of time."

Clearly, Lewis's ontological definition of determinism is distinct from more traditional semantic definitions of determinism. It is equally obvious that free will and moral responsibility are ontological concerns. If the distinction between semantic and ontological accounts of determinism matters theorists in the free will literature ought to employ the ontological concept. I assume semantic definitions of determinism are so prevalent because theorists believe that the distinction does not make a difference. I also assume Lewis did not employ a more standard definition because he disagrees. In fact, given that the logic of semantic relations is distinct from the logic of ontological relations it would be incredible if the distinction did not make a difference. A second reason that semantic definitions of determinism are so prevalent is that it is easier to think about the free will debate in these terms. Yet, given that an important distinction is being blurred, and there are good reasons to believe that the distinction makes a difference, the extra ease should be troubling. 
In fact, we have already explored one area of the free will debate where employing an ontological or semantic definition of determinism matters. The semantic definition of determinism entails that nobody is even partially responsible for anything in a deterministic world if $B \square$ is a valid inference rule. Conjoining $B \square$ with the ontological definition of determinism, however, does not produce this result. Since the ontological definition of determinism is not about semantic entailment relations, it does not provide the necessary premises for constructing the DA. Further, it is unclear what principle could replace $\mathrm{B} \square$ in order to generate a similar result on the ontological account. I believe this merely highlights that the DA initially seems plausible because of semantic ascent. Supporters of the DA, however, ought to consider replacing the semantic definition of determinism with the ontological definition and then constructing an argument similar to the DA that is rooted in ontology.

Further, given certain beliefs about time, the semantic and ontological concept of determinism are not coextensive. A-theorists about time believe that the present is ontologically privileged. B-theorists, however, claim that 'now' is an indexical. 'Here' refers to the place the speaker is located at. According to B-theorists, 'now' refers to the time the speaker is located at. A-theorists are typically either presentists or growing block theorists. On these accounts, the future is drastically different from the present. Often, these theorists claim that propositions about the future that are not metaphysically necessary are neither true nor false. Instead, they are indeterminate.

If future contingent propositions have an indeterminate truth value, the semantic definition of determinism tells us nothing about future events. The semantic definition of determinism claims that a world is deterministic if and only if a complete description of some moment conjoined with the laws of nature entails all true propositions. On these accounts of time, there are no metaphysically contingently true propositions about the future. So, all true propositions could be derived from a complete description of some past moment and the laws of nature in any world that could not branch prior to the present. If these accounts of time are correct, worlds that can branch after the present moment would still count as deterministic on the semantic definition of determinism. Yet, according to the ontological concept, worlds that could branch at any point are indeterministic regardless of what the correct account of time is. Since plausible assumptions about time entail that the semantic and ontological concept of determinism are not coextensive we ought to employ the concept we actually care about.

Even B theorists should avoid employing the semantic definition of determinism. After all, the free will debate ought not to be carried out in a manner that presupposes either account about time. If a B -theorist believes that their account of time has relevant consequences for free will, these commitments should be made explicit and argued for. Smuggling ones favorite account of time into the free will debate through semantic ascent is a strategy an intellectually honest B-theorist would not endorse.

The process of semantic ascent has also shaped the concept of laws of nature employed in the free will debate. In order to avoid complicated issues about the ontological status of laws of nature most participants in the free will debate employ a semantic conception of laws of nature. Unless laws of nature are propositions it is a category mistake to claim that the laws combined with a complete description of 
the world at a moment entail all true propositions. Only truthbearers can be the relata of an entailment relation. So, anyone who employs the semantic conception of determinism must also employ a semantic conception of laws. Yet, if laws of nature provide any credible threat to our free will, they are much more than mere propositions. Nobody has ever been pushed around by a proposition.

Humean compatibilists claim that some accounts of laws of nature seem to make determinism compatible with free will. Escaping to the semantic plane has allowed others the appearance of taking a neutral stance on the ontological status of laws. Yet, not only does the Humean account of laws have significant consequences for the free will debate, but today's main competitor to Humean accounts has even more drastic consequences. The process of semantic ascent has caused theorists in the free will literature to ignore these issues.

Today's main competitor to Humean accounts seems to be scientific essentialism. ${ }^{8}$ According to this position, statements of laws of nature are metaphysically necessary, a posteriori knowable, truths that are grounded in the essential properties of natural kinds. The free will debate needs to be drastically rephrased if statements of laws of nature are metaphysically necessary, and our laws are indeterministic. After all, if statements of laws of nature are metaphysically necessary, then it is metaphysically impossible for a world composed of objects like ours to have deterministic laws. If it is metaphysically impossible for a world composed of objects like ours to have deterministic laws, then it is metaphysically impossible for free will to exist in a deterministic world composed of objects like ours. After all adding any conjunct to a metaphysically impossible proposition produces a metaphysically impossible conjunction. It is equally metaphysically impossible for two plus two to equal four in a deterministic world composed of objects like ours as it is for free will to exist in a deterministic world with objects like ours. The fact that adding any conjunct to a metaphysically impossible proposition results in a metaphysically impossible conjunction tells us nothing important about the added conjunct.

Certainly, scientific essentialists have concerns about free will. But, if scientific essentialism is true the free will debate needs to be drastically overhauled. It is interesting that both the Humean account and its main competitor have huge implications for free will. Concentrating on semantic concepts of laws makes it easy to ignore these issues. Ignoring problems, however, does not make them go away.

It is understandable why so many of the central concepts in the free will debate are expressed in semantic terms. Until recently, many philosophers believed that semantic ascent allowed theorists to bracket ontological issues. Nevertheless, since the logic of ontological relations is distinct from the logic of semantic relations, semantic ascent is problematic. It is a mistake to employ semantic conceptions of laws and determinism when discussing free will. Once one takes the ontological turn, there are excellent reasons to believe that the DA is invalid. Yet, the ontological turn is significantly more important for free will than merely demonstrating how one argument fails. Since much of the free will literature is wedded to the linguistic turn, taking the ontological turn will significantly impact

\footnotetext{
${ }^{8}$ While there is a vast literature on scientific essentialism, Ellis 2007 is perhaps the best place to being examining this position.
} 
the literature. Since so many of the concepts that are central to free will have been expressed in semantic terms, taking the ontological turn will not be easy. Yet, there are many reasons to believe doing so will be fruitful.

Acknowledgments Author is grateful to Jeremy Byrd, Joe Campbell, Alfred Mele, and an extraordinarily helpful anonymous reviewer for the insights they provided on earlier drafts of this paper

\section{References}

Bird, A. (2010). Nature's metaphysics: Laws and properties. New York: Oxford University Press.

Ellis, B. (2007). Scientific essentialism. Cambridge, MA: Cambridge University Press.

Fara, M. (2008). Masked abilities and compatibilism. Mind, 117, 843-865.

Gundersen, L. (2002). In defence of the conditional account of dispositions. Synthese, 130, 389-411.

Gundersen, L. (2003). Dispositional theories of knowledge. Hampshire: Ashgate Publishing.

Gundersen, L. (2004). Outline of a new semantics for counterfactuals. Pacific Philosophical Quarterly, $85,1-20$.

Hermes, C. (2012). Functions and altered states in dispositional analysis: A reply to Vihvelin. Philosophical Studies, 1-7. doi:10.1007/s11098-012-9890-y.

Hermes, C., \& Campbell, J. (2012). More trouble for direct source incompatibilism: Reply to Yang. Acta Analytica, 27(3), 335-344.

Kripke, S. (1980). Naming and Necessity. Cambridge, MA: Harvard University Press.

Lewis, D. (1973). Counterfactuals. Oxford: Blackwell.

Lewis, D. (Ed.). (1986). Counterfactuals and time's arrow. Philosophical papers volume II. Oxford: Oxford University Press.

Lewis, D. (2003). Finkish dispositions. The Philosophical Quarterly. 47, 143-158.

Lycan, W. (1993). MPP RIP. In J. Tomberlin (Ed.), Philosophical perspectives, vii. Language and logic. Totowa, NJ: Roman and Littlefield.

Lycan, W. (2001). Real conditionals. Oxford: Oxford University Press.

Martin, C. B. (1994). Dispositions and conditionals. Philosophical Quarterly, 44, 1-8.

Martin, C. B. (2008). The mind in nature. New York: Oxford University Press.

McDermott, M. (2007). True antecedents. Acta Analytica, 22, 333-335.

McGee, V. (1985). A counterexample to Modus Ponens. Journal of Philosophy, 82, 462-471.

McGee, V. (2000). To tell the truth about conditionals. Analysis, 60, 107-111.

McKenna, M. (2001). Source incompatibilism, ultimacy, and the transfer of non- responsibility. American Philosophical Quarterly, 38, 37-52.

Molnar, G. (2007). Powers: A study in metaphysics. New York: Oxford University Press.

Mumford, S. (1998). Dispositions. Oxford: Oxford University Press.

Mumford, S. (2004). Laws in nature. New York: Routledge.

Ravizza, M. (1994). Semi-compatibilism and the transfer of nonresponsibility. Philosophical Studies, 75, 61-93.

Restall, G. (1996). Truthmakers, entailment, and necessity. Australasian Journal of Philosophy, 74, 331-340.

Rodriguez-Pereyra, G. (2006). Truthmakers. Philosophy Compass, 1, 186-200.

Smith, M. (2003). Rational capacities, or: how to distinguish recklessness, weakness, and compulsion. In S. Stroud \& C. Tappolet (Eds.) Weakness of will and practical irrationality (pp. 17-38). Oxford: Clarendon Press.

Stump, E. (2000). The direct argument for incompatibilism. Philosophy and Phenomenological Research, $61,459-466$.

Stump, E. (2002). Control and causal determinism. In S. Buss \& L. Overton (Eds.), Contours of agency: Essays in honor of Harry Frankfurt. Cambridge, MA: MIT Press.

van Inwagen, P. (1980). The incompatibility of responsibility and determinism. Bowling Green Studies in Applied Philosophy, 2, 30-37.

van Inwagen, P. (1983). An essay on free will. Oxford: Clarendon Press.

Vihvelin, K. (2000). Libertarian compatibilism. Nous, 34, 139-166.

Vihvelin, K. (2004). Free will demystified. Philosophical Topics, 32, 427-445. 
Vihvelin, K. (2008). Foreknowledge, Frankfurt, and the ability to do otherwise. Canadian Journal of Philosophy, 38(3), 343-372.

Vihvelin, K. (2013). Causes, laws, and free will: Why determinism doesn't matter. Oxford: Oxford University Press.

Warfield, T. (1996). Determinism and moral responsibility are incompatible. Philosophical Topics, 24, 215-226. 